\title{
Escalating placenta invasiveness: repeated placenta accreta at the limit of viability
}

\author{
This article was published in the following Dove Press journal: \\ International Journal of Women's Health \\ 15 April 2016 \\ Number of times this article has been viewed
}

\author{
Shirley Greenbaum' \\ Alla Khashper ${ }^{2}$ \\ Elad Leron' \\ Eric Ohana' \\ Mihai Meirovitz' \\ Reli Hershkovitz' \\ Offer Erez' \\ 'Department of Obstetrics and \\ Gynecology, ${ }^{2}$ Department of \\ Radiology, Soroka University Medical \\ Center, School of Medicine, Ben- \\ Gurion University of the Negev, \\ Be'er Sheva, Israel
}

\begin{abstract}
Placenta percreta is an obstetric condition in which the placenta invades through the myometrium. This is the most severe form of placenta accreta and may result in spontaneous uterine rupture, a rare complication that threatens the life of both mother and fetus. In this case report, we describe a 32-year-old woman in her fourth pregnancy, diagnosed with repeated placenta accreta, which was eventually complicated by spontaneous uterine rupture at 24 weeks' gestation. This patient had a history of abnormal placentation in prior pregnancies and previous uterine injuries. This case demonstrates a pattern of escalating placental invasiveness, and raises questions regarding the process of abnormal placentation and the manifestation of uterine rupture in scarred uteri.
\end{abstract}

Keywords: placenta percreta, uterine injury, laparoscopy, dilatation and curettage, residua, cesarean section scar, spontaneous uterine rupture

\section{Introduction}

Placenta accreta is a pathology characterized by abnormal and firm attachment of the placenta to the myometrium. ${ }^{1}$ The depth of penetration of the placental villi into the myometrium defines three severity levels of placenta accreta; accreta, increta, and percreta. Accreta, the least severe and most common of the three, occurs when the placental villi attach directly to the myometrium rather than to the decidua basalis. Increta occurs when placental villi penetrate into the myometrium. Percreta, the most rare and severe manifestation of accreta, is the invasion of the placental villi through the entire thickness of the myometrium, and even further. ${ }^{2}$

Placenta accreta tends to reoccur; however, little is known regarding the pathophysiological processes leading to this invasive placentation. The most severe complication of placenta accreta is spontaneous rupture of the uterus, which poses diagnostic challenges and management dilemmas, and can be a life-threatening event to the mother and fetus.

Herein, we describe a woman diagnosed with repeated placenta accreta that was complicated by spontaneous rupture of the uterus. This case demonstrates increasing placental invasiveness and, to the best of our knowledge, is a first report of this kind. Furthermore, repeated invasive placentation occurred at the same site, and not at the cesarean section (CS) scar, which raises a fundamental question regarding the mechanism of trophoblast implantation and location of recurrence of placenta accreta. After four consecutive pregnancies with abnormal placentation, spontaneous rupture of the uterus occurred. Understanding the processes that influence the timing and location of this life-threatening complication may set the basis for better diagnosis and management protocols.
Correspondence: Offer Erez

Department of Obstetrics and Gynecology, Soroka University Medical Center, School of Medicine, Ben-Gurion University of the Negev, Rager Boulevard, POB I5I, Be'er

Sheva 85025 , Israel

Tel +97252 2288800

Email erezof@bgu.ac.il
International Journal of Women's Health 2016:8 | | $9-123$

(c) (1) (8) ( 2016 Greenbaum et al. This work is published and licensed by Dove Medical Press Limited. The full terms of this license are available at https//www.dovepress.com/terms.php cc. hereby accept the Terms. Non-commercial uses of the work are permitted without any further permisision from Dove Medical Press Limited, provided the work is properly atributed. For permision for commercial use of this work, please see paragraphs 4.2 and 5 of our Terms (https://www.dovepress.com/terms.php). 


\section{Case report}

A 32-year-old woman in her fourth pregnancy, with parity of 2, presented at 19 weeks' gestation to the gynecologic emergency department with lower abdominal pain for the past 2 days. Her obstetric history included retained placenta in both first and second deliveries, which necessitated manual revision of the uterine cavity and curettage. She had a perforation of the left posterior uterine wall during curettage in her second delivery that was laparoscopically repaired. In her third pregnancy, she presented with an acute abdomen at 19 weeks' gestation and underwent exploratory laparoscopy that demonstrated a $2.5 \mathrm{~cm}$ rupture in the posterior uterine wall at the site of the previous perforation. Laparoscopy was turned into laparotomy; the rupture was sutured and the patient recovered well. Magnetic resonance imaging (MRI) performed at 21 weeks' gestation demonstrated placental tissue penetrating, but not perforating, the myometrium of the posterior uterine wall, which was indicative of placenta increta (Figure 1). After counseling, the couple chose to terminate the pregnancy, and hysterotomy was performed at 22 weeks' gestation.

In the current pregnancy, upon admission to the emergency department, the patient presented normal vital signs, and the gynecologic examination revealed 19 weeks' gestation - sized uterus, a closed cervix, and no vaginal bleeding. Transabdominal ultrasound scan suggested abnormal placentation (Video S1). This suspicion raised by sonography, together with the patient's history, prompted

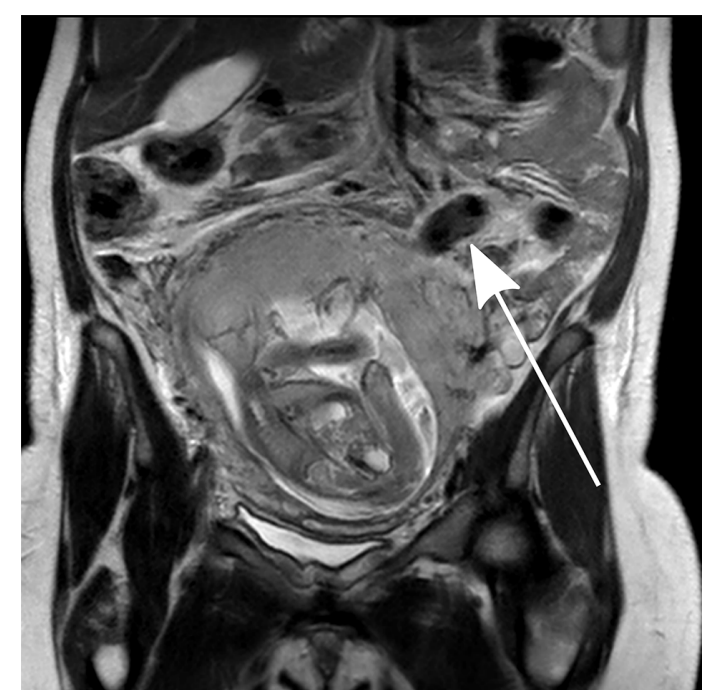

Figure I MRI of placenta increta (third pregnancy).

Notes: Coronal T2 MRI of the abdomen showing an irregular-looking posterior placenta, thinning of the myometrium, and discontinuity of the posterior uterine wall. A sigmoid loop (indicated by the arrow) is observed adjacent to the posterior uterine wall, however, it seems not to be invaded by the placenta. No dilation of the proximal or distal intestine was detected.

Abbreviation: MRI, magnetic resonance imaging. an MRI at 24.2 weeks that demonstrated the presence of placenta percreta at the site of the previous placenta increta (Figure 2A). Following counseling, the couple decided to continue the pregnancy, and the patient was hospitalized for observation. Two days later, the woman reported severe abdominal pain. Rapid bedside ultrasound examination demonstrated intraabdominal bleeding, and emergency CS was performed. During laparotomy, massive intraabdominal bleeding was observed, originating from a uterine rupture with a perforating placental tissue (Figure 2B). Following the delivery of the fetus and complete placental removal, as well as suturing of the uterine wall, the bleeding stopped and hysterectomy was avoided. The mother recovered well, while her neonate died of prematurity complications. Due to the ominous nature of the patient's obstetric history, she was advised to avoid future pregnancies.

\section{Discussion}

Placenta accreta, at any level of severity, is a rare obstetric complication with an estimated incidence of between 1 in 533 (as reported by $\mathrm{Wu}$ et $\mathrm{al}^{3}$ ) and 1 in 2,500 pregnancies (as reported by Miller et $\mathrm{al}^{1}$ ). However, once placenta accrete is diagnosed, it has a tendency to reoccur in subsequent pregnancies. ${ }^{4,5}$ Little is known about recurrence of placenta accreta, and specifically its location, histopathological invasiveness, and prognosis. The only known risk factor for repeated placenta accreta is parity. ${ }^{6}$ Here we report, for the first time, a case of four consecutive pregnancies complicated by abnormal placentation.

In primary placenta accreta, the strongest independent risk factor has been found to be previous CS. ${ }^{1,7}$ This is explained by the tendency of implantation and placentation to occur in the scarred area. ${ }^{1}$ In the case presented here, recurrence occurred in the left uterine cornu, the site of the previous placenta increta, rather than the CS scar. Additionally, the clinical manifestation was aggravated with each consecutive pregnancy: retained placenta necessitating manual lysis and curettage in the first and second, placenta increta in the third, and spontaneous uterine rupture due to placenta percreta in the fourth. Therefore, this case presents not only placenta accreta recurrence but also increased invasiveness of the placentation.

Even though placentation is prone to develop within previous CS scars, other prior uterine injuries may play a similar role, and hence are considered to be a risk factor for placenta accreta. ${ }^{7}$ It is not known whether injury location affects the risk for placenta accreta. The correlation between scarred uteri and placenta accreta is explained by a relative hypoxic environment in the scar tissue ${ }^{8}$ or the histologically abnormal 

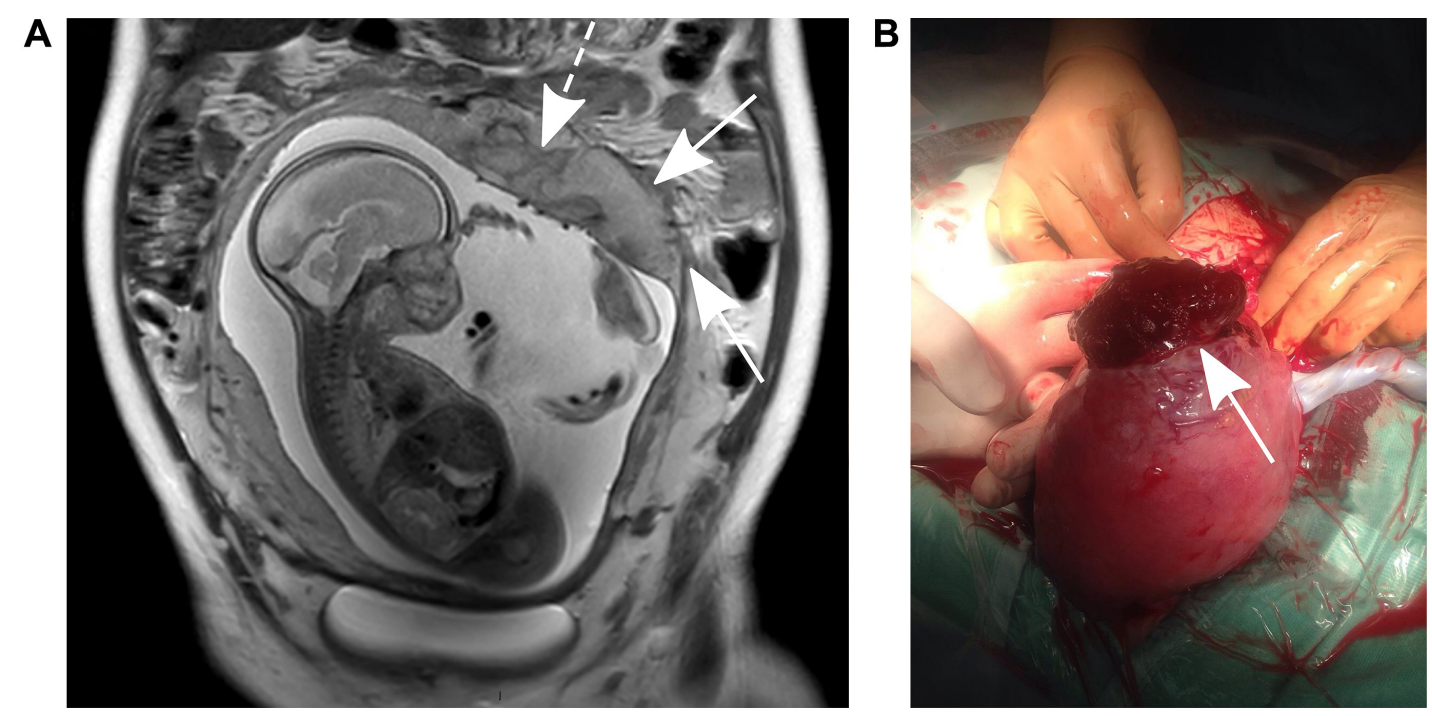

Figure 2 MRI of placenta percreta (fourth pregnancy).

Notes: (A) Coronal T2 MRI of the abdomen showing an irregular-looking posterior placenta, thinning of the myometrium, and discontinuity of the posterior uterine wall (arrows) with abnormal vascularity and prior hemorrhages (dashed arrow). (B) Placenta penetrating through $5 \times 2 \mathrm{~cm}$ uterine wall rupture in the left cornu (arrow), as observed during the surgery.

Abbreviation: MRI, magnetic resonance imaging.

structure of the scar. This abnormal structure is characterized by defective re-epithelialization and relative abundance of extracellular matrix. ${ }^{9}$ Alternatively, prior uterine injury is associated with dynamic changes in decidual leukocyte distribution, ${ }^{10}$ which subsequently affects the homing of the blastocyst to its implantation site.

Once placenta accreta is diagnosed, proper counseling and discussion with the patient should be undertaken regarding further management of the pregnancy in light of the complications involved. ${ }^{11}$ The most severe complication is spontaneous rupture of the uterus, as seen in this case, which poses both a diagnostic challenge and an immediate risk to the life of both mother and fetus. The incidence of spontaneous uterine rupture is reported to be approximately one in 5,000; however, this includes etiologies other than placenta accreta. ${ }^{12}$ Uterine rupture due to placenta accreta is extremely rare, and a systematic review of reported cases is yet to be done. In the past, most cases were managed by hysterectomy, but conservative treatment is becoming common recently. ${ }^{13,14}$ During the operation, active bleeding stopped promptly and the patient remained hemodynamically stable. Completing the procedure outweighed the risk of blood loss involved in hysterectomy, and uterine repair was technically feasible. Hence, we chose a conservative treatment approach and repaired the uterus.

The location where spontaneous uterine rupture occurs has not been thoroughly studied; however, some reports associate first trimester ruptures with the fundus and third trimester ruptures with the lower uterine segment. ${ }^{15}$ In case of previous $\mathrm{CS}$, the rupture usually occurs at the site of the old scar. ${ }^{12} \mathrm{In}$ our patient, the rupture appeared in the left uterine cornu, where the placenta was invading through the myometrium, rather than in the CS scar. This could be explained by the fact that the uterine wall was already disrupted by the placenta percreta prior to the rupture, as was seen in the MRI.

As with rupture location, factors affecting the timing of uterine rupture due to placenta accreta are unknown. While it is well established that spontaneous uterine rupture usually occurs in the third trimester, ${ }^{15}$ there have been reports of first ${ }^{8}$ and second ${ }^{16-19}$ trimester ruptures as well. In our case, spontaneous rupture occurred at 24 weeks' gestation; a critical time for the fetus. This gestational age marks the limit of viability, since preterm delivery around this time results in 50\% longterm survival probability of the newborn. ${ }^{20}$ In the face of immediate risk for the mother, urgent CS was inevitable, even when considering the probable prematurity complications for the fetus. With the increase in conservative management of placenta percreta, this case highlights the grave prognosis of pregnancies following placenta accreta. Although systematic reviews of these complications are not yet available, this insight should be taken into account during counseling following conservative management of placenta accreta.

\section{Acknowledgment}

The authors advise that the Ben-Gurion University of the Negev institutional review board does not require that 
institutional review board approval or patient consent be obtained for case reports of a single patient.

\section{Disclosure}

The authors report no conflicts of interest in this work.

\section{References}

1. Miller DA, Chollet JA, Goodwin TM. Clinical risk factors for placenta previa-placenta accreta. Am J Obstet Gynecol. 1997;177:210-214.

2. Saleh JH, Haney EI. Placenta previa and accreta. In: Sciarra JJ, editor. Gynecology and Obstetrics. Philadelphia: Lippincott Williams \& Wilkins; 2004.

3. Wu S, Kocherginsky M, Hibbard JU. Abnormal placentation: twenty-year analysis. Am J Obstet Gynecol. 2005;192:1458-1461.

4. Vinograd A, Wainstock T, Mazor M, et al. A prior placenta accreta is an independent risk factor for post-partum hemorrhage in subsequent gestations. Eur J Obstet Gynecol Reprod Biol. 2015;187:20-24.

5. Sentilhes L, Kayem G, Ambroselli C, et al. Fertility and pregnancy outcomes following conservative treatment for placenta accreta. Hum Reprod. 2010;25(11):2803-2810.

6. Gielchinsky Y, Rojansky N, Fasouliotis SJ, Ezra Y. Placenta accreta summary of 10 years: a survey of 310 cases. Placenta. 2002;23: 210-214.

7. Usta IM, Hobeika EM, Abu Musa AA, Gabriel GE, Nassar AH. Placenta previa-accreta: risk factors and complications. Am J Obstet Gynecol. 2005;193:1045-1049.

8. Timor-Tritsch IE, Monteagudo A. Unforeseen consequences of the increasing rate of cesarean deliveries: early placenta accreta and cesarean scar pregnancy. A review. Am J Obstet Gynecol. 2012;207(1):14-29.

9. Jauniaux E, Jurkovic D. Placenta accreta: pathogenesis of a 20th century iatrogenic uterine disease. Placenta. 2012;33(4):244-251.
10. Sindram-Trujillo AP, Scherjon SA, van Hulst-van Miert PP, Kanhai HH, Roelen DL, Claas FH. Comparison of decidual leukocytes following spontaneous vaginal delivery and elective cesarean section in uncomplicated human term pregnancy. J Reprod Immunol. 2004;62: 125-137.

11. Oyelese Y, Smulian JC. Placenta previa, placenta accreta, and vasa previa. Obstet Gynecol. 2006;107(4):927-941.

12. Gardeil F, Daly S, Turner MJ. Uterine rupture in pregnancy reviewed. Eur J Obstet Gynecol Reprod Biol. 1994;56:107-110.

13. Alanis M, Hurst BS, Marshburn PB, Matthews ML. Conservative management of placenta increta with selective arterial embolization preserves future fertility and results in a favorable outcome in subsequent pregnancies. Fertil Steril. 2006;86(5):1514.e3-e7.

14. Sentilhes L, Goffinet F, Kayem G. Management of placenta accreta. Acta Obstet Gynecol Scand. 2013;92:1125-1134.

15. Jang DG, Lee GS, Yoon JH, Lee SJ. Placenta percreta-induced uterine rupture diagnosed by laparoscopy in the first trimester. Int J Med Sci. $2011 ; 8: 5-8$

16. Siwatch S, Chopra S, Suri V, Gupta N. Placenta percreta: rare presentation of haemorrhage in the second trimester. BMJ Case Rep. 2013. doi:10.1136/bcr-2012-007782.

17. Matsuzaki S, Matsuzaki S, Ueda Y, et al. A case report and literature review of midtrimester termination of pregnancy complicated by placenta previa and placenta accreta. AJP Rep. 2015;1(212):6-11.

18. Dahiya P, Nayar KD, Gulati AJS, Dahiya K. Placenta accreta causing uterine rupture in second trimester of pregnancy after in vitro fertilization: A case report. J Reprod Infertil. 2012;13(1):61-63.

19. Zeeman GG, Allaire A, Whitecar P, Moise KJ. Second-trimester presentation of placenta percreta. Am J Perinatol. 1999;16(9):475-478.

20. Allen M, Donohue P, Dusman A. The limit of viability - Neonatal outcome of infants born at 22 to 25 weeks gestation. $N$ Engl J Med. 1993;329:1597-1601. 


\section{Supplementary material}

Video SI Sonography of placenta percreta (fourth pregnancy).

Notes: Transabdominal two-dimensional ultrasound in the transverse plane showing an abnormal placenta with thinning of the myometrium in the left posterior uterine wall, indicated by an asterisk. Similar findings are seen in the longitudinal plane in addition to fundal placental lacunas (arrow head) with increased blood flow by color Doppler scanning.

\section{Publish your work in this journal}

The International Journal of Women's Health is an international, peerreviewed open-access journal publishing original research, reports, editorials, reviews and commentaries on all aspects of women's healthcare including gynecology, obstetrics, and breast cancer. The manuscript management system is completely online and includes

Submit your manuscript here: http://www.dovepress.com/international-journal-of-womens-health-journa a very quick and fair peer-review system, which is all easy to use. Visit http://www.dovepress.com/testimonials.php to read real quotes from published authors. 